\title{
6
}

\section{VERBOS MODAIS NA COMUNIDADE DE SAPÉ (BA)}

MODAL VERBS IN SAPÉ (BAHIA, BRAZIL)

Maciele de Jesus Gonçalves' Universidade Federal da Bahia

Rerisson Cavalcante ${ }^{2}$ Universidade Federal da Bahia

Resumo: Descrevemos o comportamento dos verbos auxiliares modais de possibilidade e de necessidade na comunidade afrodescendente de Sapé, município de Planalto, no interior da Bahia. O objetivo é identificar como são expressas no dialeto as modalidades epistêmica, deôntica, dinâmica, teleológica e bulética (conforme definidas na literatura da Semântica Formal), com o foco especial sobre a variação entre o verbo poder e a lexia dar para na expressão de possibilidade e entre dever e ter que na expressão de necessidade. Os resultados apontam que dever está praticamente restrito à modalidade epistêmica, enquanto ter que tem alta produtividade em todas as modalidades não-epistêmicas; poder é o modal mais produtivo, ocorrendo em todos os contextos em que houve dados com valor de possibilidade, enquanto dar para tem produtividade significativa, mas está restrito aos contextos dinâmico-circunstanciais.

Palavras-Chave: Verbos Modais; Português Afrobrasileiro; Semântica; Modalidade.

1 Endereço eletrônico: macieleg@gmail.com.

2 Endereço eletrônico: rerissoncavalcante@gmail.com. 
Abstract: In this paper, we describe the behavior of modal verbs of possibility and necessity in Sapé, a black community in the municipality of Planalto, state of Bahia. Our goal is to identify how epistemic, deontic, dynamic, teleological and buletic modalities (as defined in the literature on Formal Semantics) are expressed in the dialect, with a special attention to the variation between poder ('can') and the lexia dar para (literally, 'give to'; idiomatically, 'it is possible that') for possibility and between dever ('must, should' but also 'owe') and the lexia ter que (literally, 'have that') for necessity. The results show that dever is practically restricted to the epistemic modality, while ter que is very productive in all non-epistemic modalities; poder is the most productive modal, occurring in all contexts where there was data with value of [possibility], while dar para has significant productivity, but is restricted to dynamic-circumstantial contexts.

Keywords: Modal Verbs; Afro Brazilian Portuguese; Semantics; Modality.

\section{INTRODUÇÃO}

O objetivo deste trabalho é descrever o comportamento dos verbos modais em um dialeto rural do interior da Bahia, mais especificamente em uma comunidade formada a partir de ex-escravos, que pode, portanto, ser vista como fortemente influenciada pelo contato linguístico. A justificativa para a delimitação desse tema está na variação que existe na expressão da modalidade no português brasileiro (PB) contemporâneo, descrita adiante. E a justificativa para a escolha desse corpus especificamente está na possibilidade de examinar o comportamento de um dialeto com menos influência da escolarização, bem como verificar, em fases posteriores da pesquisa, a influência do contato linguístico na alteração do sistema modal do PB.

A modalidade é uma categoria gramatical, paralela a tempo e aspecto, através da qual os falantes expressam julgamentos sobre o conteúdo e o status das proposições (cf. PALMER, 2001) e que se manifesta através de elementos linguísticos como verbos auxiliares, morfemas flexionais e advérbios.

Em um sentido mais amplo, a modalidade diz respeito a vários tipos de avaliações subjetivas do falante quanto às sentenças enunciadas. Em um sentido mais restrito, diz respeito a julgamentos de possibilidade e de necessidade do conteúdo das proposições. Neste trabalho, adotaremos esse recorte mais 
específico, uma vez que a perspectiva mais ampla se depara com alguma vagueza conceitual e com problemas na descrição da interação entre diferentes tipos de modalidade numa mesma sentença/proposição (cf. SCARDUELLI, 2011, p. 27-34; cf. também LUNGUINHO, 2010; NEVES, 2006). Dentro da visão mais restrita, adotada, por exemplo, pela Semântica Formal (cf. PIRES DE OLIVEIRA, 2014), a modalidade ainda pode ser classificada em vários tipos distintos, como epistêmica, deôntica, dinâmica/circunstancial, teleológica e bulética/bulomática.

A modalidade epistêmica expressa julgamentos sobre o status factual da proposição, sua veracidade, com base nas evidências disponíveis. Uma sentença como (1a) descreve um evento ou estado do mundo, podendo ser verdadeira ou falsa. As sentenças (1b) e (1c), por outro lado, trazem o mesmo conteúdo proposicional de (1a), mas adicionam julgamentos que indicam uma probabilidade baixa ou alta de (1a) ser verdadeira.
a. João está dormindo.
b. João pode estar dormindo.
(possibilidade epistêmica)
c. João deve estar dormindo.
(necessidade epistêmica)

Em outras palavras, (1b) expressa uma conclusão possível a respeito da situação (possibilidade epistêmica), enquanto (1c) expressa uma conclusão necessária ou, ao menos, a conclusão mais provável (necessidade epistêmica).

A modalidade deôntica exprime julgamentos de permissão, obrigação e proibição, condicionadas por fatores externos ao indivíduo como algum sistema moral, legal ou qualquer outra fonte de autoridade. A sentença ( $2 b)$ expressa uma permissão dada por uma autoridade, possivelmente pelos pais de João, constituindo um caso de possibilidade deôntica. (2c), por outro lado, expressa uma obrigação imposta a João, uma necessidade deôntica.

a. João fez/faz/está fazendo/vai fazer a lição de casa. 
b. João pode fazer a lição (depois de brincar). (permissão/possibilidade deôntica) ${ }^{3}$

c. João deve fazer a lição (antes de brincar). (obrigação/necessidade deôntica)

\section{A modalidade dinâmica ou circunstancial expressa capacidade ou} habilidade, como em (3a), ou disposição, como em (3b), que emana dos fatores condicionantes internos aos indivíduos ou situações. Em ambos os exemplos, temos possibilidade dinâmica ${ }^{4}$.
a. João pode prender a respiração por 4 min.
(possibilidade dinâmica)
b. Esse prédio pode cair a qualquer momento.
(possibilidade dinâmica)

Esses são os três principais tipos de modalidade citados na literatura, mas outros também podem ser identificados, como a modalidade teleológica, que codifica possibilidade ou necessidade em relação a um fim ou objetivo delimitado, como nos exemplos em (4), em que as opções são delimitadas em função do objetivo ou meta previamente definida de se chegar ao aeroporto ${ }^{5}$.
a. Para chegar ao aeroporto, você pode pegar a Avenida Paralela (ou a Oceânica). (possibilidade teleológica)
b. Para chegar ao aeroporto a tempo, você deve pegar a Avenida Paralela (pois a Oceânica está interditada).
(necessidade teleológica)

\footnotetext{
3 O fato de que os termos "permissão" e "obrigação" se referem especificamente aos valores deônticos não deve levar o leitor a se esquecer que estes também são valores de possibilidade e de necessidade. Infelizmente, algumas vezes a existência dos termos "permissão" e "obrigação" para o domínio deôntico faz com que alguns autores associem automaticamente os termos "possibilidade" e "necessidade" especificamente à modalidade epistêmica, gerando, inclusive, erros na classificação e na discussão dos dados, com alguns trabalhos descritivos considerando como epistêmicos todos os dados em que é possível fazer uma paráfrase com o uso do adjetivo "possível" ou do advérbio "possivelmente", o que é um equívoco.

4 Há alguma oscilação conceitual na literatura ao se lidar com a modalidade dinâmica ou circunstancial, a começar pelo rótulo. Alguns, por exemplo, usam o termo "dinâmica" e a definem apenas em termos de capacidades condicionadas internamente ao indivíduo, o que excluiria algumas disposições presentes muito mais numa situação ou num local do que num indivíduo, por exemplo. Isso sugeriria que a modalidade circunstancial é outro tipo modal, distinto da dinâmica. Outros usam dinâmica e circunstancial como sinônimos, mas definem essa modalidade como definida por um conjunto de circunstâncias (cf. von FINTEL, 2006). Aqui, adotaremos uma visão mais ampla, considerando como um único tipo modal, sem, entretanto, negar a possibilidade de desdobrá-la em dois subtipos.

5 Parece-nos que a modalidade teleológica é uma espécie de modalidade dinâmica/circunstancial relativizada a um objetivo explicitado no contexto.
} 
Outro tipo de modalidade menos citado é a bulética ou bulemática, que expressa possibilidade ou necessidade em função dos desejos do falante. Nos exemplos em (5), o falante está expressando o seu desejo de que chova amanhã ou de que alguém seja fisicamente punido por algo que fez .
a. Bem que podia chover amanhã!
(possibilidade bulética)
b. Ele devia levar um murro pelo que fez. (necessidade bulética)

Nos exemplos vistos até aqui, poder e dever são neutros quanto ao tipo de modalidade, diferindo entre si apenas na força modal que expressam: possibilidade ou necessidade. O tipo modal é definido pela interação do verbo com os demais elementos da frase e do contexto linguístico e extralinguístico.

Além de poder e dever, dois outros verbos auxiliares também expressam valores modais no PB. O primeiro é a lexia ter que (ou ter de), que tipicamente codifica o valor de necessidade deôntica, como em (6), alternando com dever.
a. João tem que fazer a lição (antes de brincar).
(necessidade deôntica)
b. João deve fazer a lição (antes de brincar). (necessidade deôntica)
c. A plateia tem que ficar em silêncio durante o debate. (necessidade deôntica)
d. A plateia deve ficar em silêncio durante o debate.
(necessidade deôntica)

Por um lado, ter que parece expressar um valor mais forte do que dever, como se pode ver no par em (7), em que a oração com dever pode ser reforçada por outra com ter que, mas o inverso parece inadequado (cf. SCARDUELLI, 2011, p. 63). Esse fato pode ser descrito em termos de necessidade fraca (codificada por dever) versus necessidade forte (codificada por ter que).

\footnotetext{
6 Não incluímos aqui o uso de outros tipos de verbos que indicam especificamente volição, como querer e desejar, pois não se tratam de verbos auxiliares (não sendo, portanto, a gramaticalização da modalidade) e não expressam valores de possibilidade e necessidade, fugindo, assim, da visão mais restrita de modalidade adotada neste trabalho. Perspectivas funcionalistas, que incluem na modalidade várias outras atitudes subjetivas, incluiriam esse tipo de verbo, mas, em nossa visão, estariam lidando com outro tipo de fenômeno.
} 
b. \#Paulo não só tem que lavar os pratos, como deve. ${ }^{7}$

Por outro lado, ter que parece estar substituindo dever. Em contextos coloquiais, com valor deôntico, ter que é mais natural e produtivo do que dever, que, por sua vez, é mais típico de linguagem formal, como leis e textos oficiais (cf. PESSOTTO, 2014, p. 59), como se pode ver no contraste em (8).

(8) a. Os eleitores devem cadastrar a biometria até o final do mês.

b. Os eleitores têm que cadastrar a biometria até o final do mês.

O modal ter que também ocorre facilmente em contextos teleológicos, como em (9), que (em nosso próprio julgamento) soa até mais natural num uso coloquial do que $(4 \mathrm{~b})$ com dever.

(9) Para chegar ao aeroporto a tempo, você tem que pegar a Avenida Paralela (pois a Oceânica está engarrafada).

(necessidade teleológica)

Semelhantemente, ter que pode ocorrer em contextos buléticos, como em (10), e em contextos dinâmicos, como em (11). Exemplos como em (11) são importantes, pois a literatura sobre modalidade pouco fala sobre a expressão de necessidade dinâmica, o que se pode perceber inclusive pelas definições dadas, que focam mais no aspecto da expressão da capacidade ou habilidade.

(10) a. Eu tenho que comprar aquele carro de qualquer jeito! (necessidade bulética) b. A gente tem que ganhar esse sorteio! (necessidade bulética)

(11) a. Eu tenho que ir ao banheiro. (necessidade dinâmica) b. O paciente tem que fazer essa cirurgia imediatamente. (necessidade dinâmica)

7 O símbolo \# indica que a sentença é semanticamente anômala. 
É importante notar que a troca de ter que por dever em (10) e (11) não parece adequada, provocando mudança na interpretação das sentenças. Os exemplos em (12) soam como epistêmicos, indicando certeza e não desejo. (13a) soa como necessidade deôntica, como uma imposição externa, o que torna, inclusive, o exemplo pouco plausível. E (13b) parece ambíguo entre necessidade epistêmica (a cirurgia já está marcada e tudo está em preparação) ou deôntica (se a frase é usada como uma ordem do médico).

(12) a. Eu devo comprar aquele carro de qualquer jeito! (necessidade epistêmica) b. A gente deve ganhar esse sorteio! (necessidade epistêmica)

(13) a. \#Eu devo ir ao banheiro. (necessidade deôntica)

b. O paciente deve fazer essa cirurgia imediatamente. (necessidade epistêmica / dinâmica)

Parece que o verbo dever só pode ocorrer com valor dinâmico se vier flexionado no pretérito imperfeito ou no futuro do pretérito (casos em que é ambíguo com uma interpretação deôntica), como mostra o contraste em (14). Scarduelli (2011), por exemplo, trabalha com a hipótese de que deve e devia são dois modais diferentes, com especializações distintas. Ideia semelhante existe em Pessotto (2011) para as formas pode e podia.

(14) a. Eu devia/deveria ir no banheiro (logo/antes de sairmos). (necessidade dinâmica)

b. Eu devia/deveria ter ido no banheiro (logo/antes de sairmos). (necessidade dinâmica) c. \#Eu devo ir/ter ido no banheiro (logo/antes de sairmos). (necessidade dinâmica)

Por outro lado, o uso de ter que no contexto epistêmico é bem mais raro. Há autores que consideram que esse modal não ocorre na modalidade epistêmica (cf. PESSOTTO, 2014). Algo que ilustra bem esse fato é que os exemplos com dever em (6) podem facilmente receber interpretações epistêmicas, equivalentes a (15). Essa interpretação epistêmica não parece ser possível para as contrapartes com ter que em (6). 
(15) a. (Pelo que sei de João) É provável que ele (sempre) faça a lição antes de brincar.

b. (Pelo que sei sobre esse local) A plateia provavelmente fica em silêncio durante o espetáculo.

Lunguinho (2010, p. 122), por outro lado, assume que ter que pode expressar modalidade epistêmica, como no exemplo (16), retirado do texto do autor. Também nesse caso, o ter que parece ter um valor mais forte do que dever. Enquanto dever expressa a conclusão mais provável diante das circunstâncias, ter que parece expressar a única conclusão possível no cenário.

(16) (Em vista das evidências disponíveis) Pode/deve/tem que haver alguém em casa.

Ainda assim, exemplos de ter que em contextos epistêmicos parecem ser menos frequentes e mais difíceis de serem formulados sem haver ambiguidade com outros tipos de modalidade.

Outro elemento verbal utilizado com o valor modal é a lexia dar para (cf. DUARTE, 2012; AUGUSTO, 2015), que expressa tipicamente possibilidade dinâmica, alternando com poder, em exemplos como (17) ${ }^{8}$.
a. Você pode falar mais baixo?
b. Dá pra você falar mais baixo?
c. João pode vencer essa corrida.
d. Dá pra João vencer essa corrida.

Sintaticamente, esse modal se comporta de modo diferente dos demais, pois, apesar de também tomar um infinitivo como seu complemento, não exige o alçamento de um argumento do verbo principal para a posição de sujeito matriz.

8 Duarte (2012) trabalha apenas com a distinção entre modalidade epistêmica e deôntica, sem citar outros tipos, e, então, classifica dados dinâmicos de dar para como epistêmicos. Coelho e Silva (2014), sem explicitar nenhuma tipologia de classificação modal, consideram os usos modais dessa lexia como epistêmicos por oposição aos demais usos de dar como verbo pleno, verbo leve e auxiliar aspectual. Já Augusto (2015), apesar de citar a existência da modalidade dinâmica, acaba classificando, sem discussão, dados dinâmicos de dar para como epistêmicos (p. 54-57), além de incluir nessa categoria também alguns dados dinâmicos com poder. 
De fato, o alçamento do sujeito cancela a leitura modal e dispara uma leitura aspectual, descrevendo o início de um hábito (cf. COELHO; SILVA, 2014) ${ }^{9}$, como em (18a), equivalente a $(18 b)$ :

João deu pra caminhar na praia todo dia de manhã. (leitura aspectual) = 'João começou a caminhar na praia todo dia de manhã.'

Outra diferença é que dar para não parece ser produtivo em outros tipos de modalidade além da dinâmica. É mais difícil formular exemplos deônticos, teleológicos e buléticos com esse verbo. Ainda assim, é possível formular os seguintes exemplos teleológicos em (19), um dado que ainda tem certo sabor dinâmico/circunstancial (vide nota de rodapé 3).

Para chegar ao aeroporto, dá pra (você) pegar a Avenida Paralela (ou a Oceânica). (possibilidade teleológica)

Exemplos deônticos, embora difíceis, também são possíveis em alguns contextos, como em (20). Tais exemplos parecem extensões dos usos dinâmicos.

a. Professor, dá pra entregar o trabalho na próxima semana?

(possibilidade deôntica)

b. Pela lei, dá pra andar com a habilitação por até um mês depois de vencida.

(possibilidade deôntica)

Exemplos buléticos, no entanto, são bem difíceis de serem formulados com dar para, como mostram os dados em (21), em que a interpretação bulética parece falhar em favor de uma interpretação dinâmica.
a. \#Dava pra chover amanhã.
(possibilidade bulética)
b. \#Dava pra ele levar um murro pelo que fez.
(possibilidade bulética)

\footnotetext{
9 Por outro lado, Lurian da Silveira Chaves e Leonor Simioni da Unipampa (comunicação pessoal) têm analisado dados de dar para que apresentam valor modal mesmo em contexto de alçamento.
} 
Outra diferença é que, ao contrário do que se vê em dever e ter que, não parece haver diferença de força modal entre dar para e poder, ambos expressando simplesmente o valor de possibilidade. Há sim uma diferença em termos de registro, com dar para sendo mais coloquial do que poder, mas ainda assim não parece ser o caso de poder estar se tornando restrito a contextos formais. Este verbo ainda é produtivo na fala coloquial.

Em resumo, no $\mathrm{PB}$, há uma alternância entre dever e ter que, expressando necessidade, especialmente em contexto deôntico, e uma alternância entre poder e dar para, expressando possibilidade, especialmente em contexto dinâmico. As lexias ter que e dar para (especialmente esta última) são bem mais recentes na língua do que suas contrapartes. Diante desse quadro, a presente pesquisa tem como objetivo descrever quais são os verbos modais utilizados na comunidade rural afrodescendente de Sapé, Bahia. Assim, é possível verificar a produtividade desses quatro verbos modais em um dialeto com pouca influência da escolarização e com um histórico mais forte de contato linguístico durante a sua formação - algo que será mais explorado na continuação da pesquisa.

\section{METODOLOGIA}

Para esta pesquisa, foi utilizado o corpus do Português Afro-Brasileiro do Estado da Bahia (cf. LUCCHESI et al., 2009), elaborado pelo Projeto Vertentes ${ }^{10}$, da Universidade Federal da Bahia, fundado pelo Prof. Dr. Dante Lucchesi e atualmente coordenado pelo Prof. Dr. Gredson dos Santos. A coletânea selecionada é constituída por 12 entrevistas sociolinguísticas de caráter informal, realizadas na comunidade rural de Sapé, no município de Valença, no interior da Bahia. As entrevistas estão organizadas por variáveis sociais, tais como: idade

10 Disponível em: <www.vertentes.ufba.br>. 
(faixa 1: de 20 a 40 anos; faixa 2: de 40 a 60 anos; faixa 3: mais de 60 anos), sexo e nível de escolaridade (analfabeto/semianalfabeto).

A partir das transcrições grafemáticas dos áudios das entrevistas, foi possível fazer o levantamento das ocorrências dos auxiliares modais, que foram classificados de acordo com a modalidade expressa.

O objetivo principal da pesquisa é verificar quais verbos modais expressam cada tipo de modalidade no dialeto em questão. Entre os objetivos específicos, temos como foco a alternância entre poder e dar para e a alternância entre dever e ter que. Algumas perguntas específicas que esta pesquisa visa a responder são:

a) ter que e dever são igualmente produtivos em contexto deôntico no dialeto?

b) ter que ocorre em outros tipos de modalidade além da deôntica?

c) dar para ocorre em outras modalidades além da dinâmica?

d) dar para permite alçamento de argumento, mantendo o valor modal?

e) que formas flexionais de dever ainda mantêm o valor deôntico?

Além dessas perguntas principais, a pesquisa também esperava verificar se a forma possa ocorria no dialeto em sentenças matrizes sem elementos licenciadores de subjuntivo, alternando com pode, como nas sentenças em (22). Trata-se de um uso que é um estereótipo (no sentido sociolinguístico do termo) de fala de informantes rurais e/ou menos escolarizados.

(22) a. Possa/pode ser que ele saiu. (possibilidade epistêmica) b. Possa/pode ser que ele vença a corrida. (possibilidade dinâmica)

Na próxima seção, apresentamos os resultados da pesquisa. 
Foram encontradas 282 (duzentos e oitenta e duas) ocorrências dos quatro verbos modais em estudo. A Tabela 1, abaixo, mostra a quantidade e percentual de cada um dos verbos, sem distinguir o valor modal e o tipo de modalidade codificada, o que será discriminado adiante.

Tabela 1: Verbos auxiliares modais na comunidade de Sapé (Valença, Bahia)

\begin{tabular}{ccccc}
\hline Poder & Dar para & Dever & Ter que & Total \\
\hline 153 & 26 & 9 & 94 & 282 \\
$53,9 \%$ & $9,21 \%$ & $3,19 \%$ & $33,33 \%$ & $100 \%$ \\
\hline
\end{tabular}

Fonte: Elaborada pelos autores.

Poder e ter que foram os modais que mais ocorreram no corpus, respectivamente com 153 e 94 casos, o que equivale a 53,9\% e 33,33\% dos dados. Em seguida, vem dar para, com 26 dados, 9,21\%. O verbo dever foi o menos frequente em todo o corpus, ocorrendo apenas nove vezes, o que equivale a 3,19\% dos dados. Chama atenção como poder e dever, os dois verbos que podem ser vistos como as variantes mais conservadoras e de prestígio (no sentido da sociolinguística laboviana), apresentam um comportamento oposto quanto à frequência, sendo respectivamente o mais frequente e o menos frequente.

Os exemplos em (23) ilustram os dados modais encontrados no dialeto.

(23) a. Se quisé ir... pode, ele conversa. (SP-inq05)

b. Deve sê gente com vontade de dizê alguma coisa... (SP-inq01)

c. Aí agora tem que ir pra... pra o forno... po fogo. (SP-inq12)

d. Aí num deu pa sai(r). (SP-inq01)

Os dados com verbos modais foram classificados de acordo com o tipo de modalidade expressa. A Tabela 2 revela uma diferença na quantidade de dados de cada modalidade. A modalidade epistêmica foi identificada somente em 15 frases, 5,31\% do total, enquanto que a modalidade deôntica teve muito mais 
ocorrências, 77 dados, 27,3\% do total. Mas a modalidade que ocorreu em maior quantidade foi a dinâmica/circunstancial, com 142 dados, o equivalente a quase metade de todos os dados do corpus, i.e., 50,35\%. Houve também 20 dados de modalidade teleológica e apenas seis dados de bulética, o que corresponde a $7,09 \%$ e $2,12 \%$ dos dados, respectivamente.

Tabela 2: Classificação dos tipos de modalidade em Sapé (BA)

\begin{tabular}{ccccccc}
\hline Epistêmica & Dinâmica & Deôntica & Teleológica & Bulética & Não-classificados & Total \\
\hline 15 & 142 & 77 & 20 & 6 & 22 & 282 \\
$5,31 \%$ & $50,35 \%$ & $27,3 \%$ & $7,09 \%$ & $2,12 \%$ & $7,8 \%$ & $100 \%$ \\
\hline
\end{tabular}

Fonte: Elaborada pelos autores.

Houve ainda um total de 22 dados, 7,77\% do total, que não foram classificados, 13 deles por serem ambíguos entre mais de uma modalidade, o que impossibilitou a classificação, e outros nove dados que, com base apenas na transcrição grafemática, sem mais elementos contextuais, não se encaixavam claramente em nenhuma das categorias de análise.

Evidentemente, o percentual de cada modalidade presente no corpus não resulta de características específicas do dialeto, mas sim das temáticas abordadas nas entrevistas, uma vez que as diferentes modalidades não estão em competição entre si. De qualquer forma, os resultados foram positivos para a pesquisa, devido à nossa atenção prioritária sobre a modalidade deôntica e dinâmica, onde se concentram as alternâncias dever/ter que e poder/dar para.

Abaixo, de (24) a (29), apresentamos alguns dados retirados do corpus em estudo, classificados por modalidade:

(24) Modalidade epistêmica

a. Só deve sê tosse, né, por que um pobrema que nada deu jeito. (SP-inq02)

b. Só podia sê barão. (SP-inq10)

(25) Modalidade dinâmica

a. Eu num posso trabaiá [de novo] que... se não é ruim, né? (SP-inq07) 
b. Pedro disse que ia trazê a namorada pr'aqui. Trôxe tá ali na venda. Aí num deu pa sai(r). (SP-inq01)

(26) Modalidade deôntica

a. tem que mantê a responsabilidade dele pra ele sê responsável, não irresponsável... (SP-inq02)

b. Os pai não pode mais, imagine ${ }^{11}$. (SP-inq06)

(27) Modalidade teleológica

a. ['Cê] tem que dêxá os menino na bêrada que ele vem... bem alto ${ }^{12}$. (SP-inq01)

b. Só a gente mesmo que morava. A num sê, pa vê alguma pessoa, a gente tinha que vim aqui em cima. (SP-inq01)

(28) Modalidade bulética

a. Aqui teve segundo turno, podia ficá aquele... (SP-inq05)

b. Rapaz, o plano d'eu... eu consegui uma família pa mim agora é só fazê minha casa. Eu penso, né. não sei se vai dá certo ô não a casa que primeiro eu tenho que fazê. (SP-inq05)

Já em (29), dois exemplos de dados que não foram classificados. Em (29a), há trechos ininteligíveis e ainda dúvida quanto à audição da palavra "escorar". Em (29b), há dúvida quanto à classificação deôntica ou teleológica.

(29) Dados problemáticos

a. Se ININT que batê, 'cê vai deixá? Tem que [escorá]. (SP-inq01)

b. É, eu e ela tem que pagá é quatorze reais [e] quano vai pa lá, e aí... até que agora... o derradêro pré-natal que ela vai... já fez... (SP-inq12)

A Tabela 3 mostra os resultados para cada verbo modal por faixa etária. $\mathrm{O}$ objetivo dessa classificação etária foi verificar se algum desses verbos está em processo de mudança linguística, por exemplo, verificar se a lexia dar para, por ser uma variante mais recente no $\mathrm{PB}$, estava presente em todas as faixas etárias ou apenas nas mais jovens. Outro exemplo é o caso do verbo dever. Olhando para a faixa etária, queríamos verificar se tal verbo caía ou aumentava em frequência das faixas mais velhas para as mais jovens. No primeiro caso, isso poderia sugerir

11 Contexto: sobre os pais baterem nos filhos.

12 Contexto: para tomar banho em determinado rio. 
que dever está sendo substituído progressivamente por ter que. No segundo caso, poderia indicar que dever já tinha um uso mais reduzido em gerações mais velhas, mas vinha sendo recuperado por uma maior exposição das gerações mais jovens a formas mais urbanas e escolarizadas de linguagem, por exemplo, através da expansão do acesso à televisão e à imprensa.

Tabela 3: Uso dos verbos modais por faixa etária

\begin{tabular}{cccc}
\hline & $\begin{array}{c}\text { Faixa } 1 \\
(20 \text { a } 40 \text { anos })\end{array}$ & $\begin{array}{c}\text { Faixa } 2 \\
\text { (40 a 60 anos) }\end{array}$ & $\begin{array}{c}\text { Faixa 3 } \\
\text { (mais de 60 anos) }\end{array}$ \\
\hline Poder & 35 & 56 & 62 \\
Dar para & 11 & 8 & 7 \\
Dever & 4 & 5 & 0 \\
Ter que & 34 & 33 & 27 \\
\hline
\end{tabular}

Fonte: Elaborada pelos autores.

O resultado que chama a atenção na Tabela 3 é justamente o do verbo dever, que é completamente ausente na faixa etária mais velha, um resultado mais compatível com a segunda das hipóteses cogitadas para o comportamento desse verbo no tempo aparente. Ou seja, parece que dever já tinha tido o seu uso modal bastante reduzido ainda nas gerações mais velhas. Por outro lado, é preciso reconhecer que, mesmo nas gerações mais jovens, esse verbo tem poucas ocorrências. Não é possível, portanto, confirmar a hipótese de que esse verbo voltou à fala da comunidade devido ao aumento da influência de fontes externas à comunidade. Tais números entre a faixa I e II podem significar apenas que esse verbo nunca caiu completamente em desuso no dialeto, apesar de ter se tornado mais raro.

A lexia dar para apresenta um leve aumento da faixa etária mais velha para a mais jovem, mas a quantidade de dados é muito pequena para qualquer conclusão.

O modal que tem a distribuição mais equilibrada por todas as faixas etárias, sem grandes alterações, é justamente a lexia ter que. Já o modal poder tem 
uma grande queda em quantidade das faixas etárias mais velhas para a mais nova. Esse resultado, entretanto, precisa ser analisado em mais detalhes, em função de cada modalidade, uma vez que, como se pode ver na Tabela, essa queda na frequência de poder não é proporcional ao aumento de dar para.

Nas próximas subseções, tratamos dos resultados discriminados por cada tipo de modalidade.

\subsection{Modalidade epistêmica no corpus}

Como exposto na Tabela 2, foram encontradas 15 sentenças com valor modal epistêmico no corpus da comunidade de Sapé. Desse total, sete dados contêm o verbo poder, que marca possibilidade epistêmica, e outros sete contêm o verbo dever, de necessidade (fraca) epistêmica. Apesar da quantidade igual, há uma importante assimetria entre poder e dever. Os sete epistêmicos de poder correspondem a apenas $4,57 \%$ de todos os 153 dados desse verbo no corpus, enquanto os sete dados de dever equivalem à quase totalidade dos casos desse verbo, que ocorreu apenas nove vezes em todo o corpus. Todos os casos de dever epistêmicos vêm flexionados no presente do indicativo (mais especificamente, na terceira pessoa). Já quanto aos dados de poder, quatro estão no pretérito imperfeito podia, e três estão no presente do indicativo pode. Nenhum dado epistêmico de dever ou poder ocorreu em outro tempo verbal. Não houve, portanto, nenhum caso do subjuntivo possa em contexto matriz sem licenciador.

E quanto aos outros dois verbos modais? Apesar da alternância que há entre poder e dar para em outras modalidades, não foi encontrado nenhum dado dessa lexia com valor epistêmico no corpus.

Com relação a ter que, a princípio, muitos autores consideram que essa lexia não é compatível com a modalidade epistêmica, mas vimos na Introdução 
que Lunguinho (2010) assume a possibilidade desse verbo codificar esse tipo de modalidade, como no exemplo (16), repetido aqui em (30).

(30) (Em vista das evidências disponíveis) Pode/deve/tem que haver alguém em casa.

Um dos objetivos da pesquisa foi verificar, então, se ter que ocorria no corpus com o valor epistêmico. Houve um dado com ter que, cuja leitura, na verdade, não é tão clara, podendo ter interpretação epistêmica ou dinâmica. É o dado apresentado em (31), com tem que demorar, em referência à construção de uma casa, um trecho que, no contexto, pode ser entendido como um quase sinônimo para deve demorar.

(31) Não comprei ainda por que tem que demorá, porque a pessoa que recebe dinhêro, compra tudo quanto e coisa... é com demora na certa! (SP-inq11)

Outra interpretação possível seria a dinâmica, com o sentido de uma pessoa pobre, justamente por ter poucos recursos, deve esperar, ou seja, deve/precisa fazer as coisas de modo mais devagar, deve demorar para comprar as coisas. Esse sentido não seria de uma obrigação (necessidade deôntica), pois não seria resultado de algum código moral ou por uma fonte de autoridade, mas uma restrição intrínseca às próprias características (financeiras, no caso) da pessoa. Ainda que consideremos a interpretação epistêmica a mais provável para (31), registramos aqui essa ambiguidade, para ficar claro como o uso epistêmico de ter que é mais difícil de ser expresso.

Os números quanto à modalidade epistêmica no corpus de Sapé estão discriminados na Tabela 4 abaixo.

Tabela 4: Verbos modais epistêmicos em Sapé (BA)

\begin{tabular}{ccccc}
\hline Poder & Dar para & Dever & Ter que & Total \\
\hline 7 & 0 & 7 & 1 & 15 \\
$46,66 \%$ & $0 \%$ & $46,66 \%$ & $6,66 \%$ & $100 \%$ \\
\hline
\end{tabular}

Fonte: Elaborada pelos autores. 
Na próxima subseção, tratamos da realização da modalidade deôntica.

\subsection{Modalidade deôntica no corpus}

Como apontado anteriormente, na Tabela 2, houve 77 dados deônticos no corpus da comunidade de Sapé, o equivalente a 27,3\% dos dados, uma quantidade bastante superior à da modalidade epistêmica. Na Tabela 5, estão apresentadas as quantidades de sentenças deônticas por verbo modal utilizado.

Tabela 5: Verbos modais deônticos em Sapé (BA)

\begin{tabular}{ccccc}
\hline Poder & Dar para & Dever & Ter que & Total \\
\hline 38 & 0 & 2 & 37 & 77 \\
$49,35 \%$ & $0 \%$ & $2,59 \%$ & $48,05 \%$ & $100 \%$ \\
\hline
\end{tabular}

Fonte: Elaborada pelos autores.

Como esperado, não houve nenhum dado deôntico com o modal dar para, fortalecendo a hipótese de que essa lexia não ocorre facilmente com esse tipo de modalidade. Isso não se deveu à falta de dados com o valor de possibilidade deôntica no corpus, pois o verbo poder ocorreu 38 vezes nos inquéritos. Novamente, as formas flexionais de poder que ocorreram foram no presente do indicativo e no pretérito imperfeito. Foram 35 casos do presente, sendo 33 de pode e dois de posso; e três casos do pretérito podia. Não houve casos do subjuntivo possa em contexto matriz.

Com relação a dever e ter que (os únicos modais que podem estar em variação estrita no contexto deôntico) os resultados mostram uma grande disparidade. A lexia ter que ocorre quase categoricamente: 37 dos 39 dados de necessidade deôntica são com ter que. O verbo dever aparece, portanto, apenas duas vezes, um resultado não esperado. Embora esperássemos que a frequência de ter que fosse maior do que a de dever, devido ao caráter aparentemente mais 
formal deste último, não esperávamos que os números deste fossem tão baixos. Considerando que os informantes do corpus são de baixa escolaridade, esses resultados são compatíveis com a interpretação de que o uso deôntico de dever sobrevive ainda no PB (urbano) falado graças à escolarização.

Outro aspecto que reforça a hipótese de progressiva substituição de dever por ter que no PB coloquial e, principalmente, no dialeto em questão é o fato de que nenhum dos dados de dever deôntico ocorre no presente do indicativo. Um dado traz a forma do pretérito imperfeito devia (cf. SCARDUELLI, 2011). Outro traz a forma do futuro do pretérito deveria. Ambos são apresentados abaixo. É importante notar que os dados não expressam uma obrigação atual, mas virtual, quase um desejo por parte do informante, o que coloca esses casos no limite entre deônticos e buléticos: ao invés de apontar que algo é ou será uma obrigação, (33) sugere que o correto seria que essa ação fosse uma obrigação.

(33) quem tem muita terra pura deveria dar pá quem trabaia... (SP-inq06)

A situação é bem diferente com ter que. Dos 37 dados deônticos com ter que, 27 estão no presente do indicativo. Além disso, oito estão no pretérito imperfeito (tinha que), um está no pretérito perfeito (teve que) e um está no infinitivo (ter que). O dado com teve que marca outra diferença quanto a dever, uma vez que o verbo dever é defectivo em qualquer uso modal (deôntico ou nãodeôntico), sendo agramatical no pretérito perfeito, como mostra o contraste em (34). Ter que é, portanto, capaz de expressar mais distinções temporais/aspectuais do que dever, algo que possivelmente contribuiu para a expansão da forma, tomando o lugar de dever.

(34) a. João deve/devia/deveria sair.

b. João deve/devia/deveria ter saído.

c. *João deveu sair. 
A seguir, tratamos dos resultados quanto à modalidade dinâmica.

\subsection{Modalidade dinâmica no corpus}

Como apontado anteriormente, a modalidade dinâmica foi a que mais ocorreu no corpus. Foram encontrados 142 dados dessa modalidade. A Tabela 6 abaixo traz os números referentes a cada verbo auxiliar utilizado.

Tabela 6: Verbos modais dinâmicos em Sapé

\begin{tabular}{ccccc}
\hline Poder & Dar para & Dever & Ter que & Total \\
\hline 93 & 26 & 0 & 23 & 142 \\
$65,49 \%$ & $18,3 \%$ & $0 \%$ & $16,19 \%$ & $100 \%$ \\
\hline
\end{tabular}

Fonte: Elaborada pelos autores.

O modal dinâmico mais encontrado foi poder, com 93 casos, o que corresponde a 65,49\% dos dados. Em segundo lugar, vem a lexia dar para, com 26 dados, que equivale a 18,3\%. Houve também 23 dados de ter que, 16,19\%, classificados como necessidade dinâmica, confirmando a hipótese de que a modalidade dinâmica não está limitada apenas ao valor de possibilidade (capacidade, habilidade, disposição). Já quanto ao verbo dever, nenhum dado com esse modal foi encontrado no corpus, confirmando a tendência de que esse modal tem distribuição bem mais restrita e que resiste ao contexto dinâmico.

Quanto à variação entre os dois modais que expressam possibilidade dinâmica, vemos no corpus a presença significativa da lexia dar para, mas o verbo poder ainda é muito mais usado para a expressão desse valor. Considerando apenas os dois verbos, que somam 119 dados, temos 78,15\% de poder e 21,84\% de dar para. Em outras palavras, a variação entre poder e dar para no contexto dinâmico mostra um perfil bem diferente da variação entre dever e ter que no contexto deôntico. Enquanto ter que praticamente tomou o lugar de dever como 
verbo modal de necessidade deôntica, poder e dar para estão apenas em variação um com o outro, com a forma mais antiga e mais conservadora poder ainda sendo bem mais produtiva do que a forma inovadora dar para.

Quanto às flexões verbais, o verbo poder no contexto dinâmicocircunstancial é o que exibe a maior variação de formas em todo o corpus. Foram 38 dados no presente do indicativo (28 com pode e 10 com posso), 27 no pretérito imperfeito (podia), dois dados no pretérito perfeito (um pude e um pôde), dois dados no futuro do subjuntivo (puder), um dado no futuro do pretérito (poderia) e um dado no pretérito do subjuntivo (pudesse). Também houve 15 dados do infinitivo (poder) e sete dados no gerúndio (podendo). Em (35), alguns exemplos de poder dinâmico encontrados no corpus.

(35) a. Só pa podê ir pa festa. (SP-inq01) $)^{13}$

b. Bom, pode sê assim uma... é alguma impressão que a gente pode tê assim... (SP-inq12)

c. Quando eu não posso, minha rôpa ela lava. (SP-inq11)

d. se eu podê andá? Viva a Deus! (SP-inq11)

A lexia dar para mostra uma variedade flexional bem maior do que a encontrada para os casos do verbo dever (em qualquer modalidade), mas ainda assim mais reduzida do que a variedade documentada para o verbo poder. Foram 17 casos com o presente do indicativo (dá para), sete casos do pretérito imperfeito (dava para) e dois casos do pretérito perfeito (deu para). Em (36), alguns exemplos de dar para dinâmico encontrados no corpus.

(36) a. Duzentos reais (...) Dá pá uma pessoa comê trinta dia? (SP-inq02)

b. ... e num dava pa distribuí pra todo mundo. (SP-inq03)

c. ... mai num deu pra pra comprá ainda não. (SP-inq09)

d. Dava pa vivê todos dois tranquilo. (SP-inq12)

Em (37), alguns exemplos de ter que dinâmico encontrados no corpus.

13 Contexto: arranjou um namorado para ter com quem ir a uma festa. 
(37) a. Era o jeito que tinha era ir, porque a gente tá doente tinha querer? Tinha que ir, minha filha. (SP-inq11)

b. Num pode largá... num pode largá no pé de cacau, tem que tirá... [quando tivé] cinco... seis, tem que tirá tudo. (SP-inq10)

A seguir, os resultados quanto à modalidade teleológica.

\subsection{Modalidade teleológica no corpus}

A modalidade teleológica ocorreu 20 vezes no corpus. Apesar da pouca quantidade, esse tipo modal superou até mesmo os dados epistêmicos, que foram apenas 15. Todos os 20 dados tiveram a interpretação de necessidade, sem nenhum dado de possibilidade. Quanto ao modal utilizado, 100\% dos dados são com a lexia ter que, nenhum com dever, o que reforça a hipótese de que ter que vem tomando o espaço do dever nos contextos não-epistêmicos.

Quanto à flexão do verbo ter que, há alguma diversidade nos dados. Foram 16 casos no presente do indicativo, $80 \%$, sendo um dado na $1^{\underline{a}}$ pessoa (tenho que) e 15 na $3^{\text {a }}$ pessoa (tem que/de), quatro ocorrências no pretérito imperfeito (tinha que), correspondente a 20\%. Em (39), alguns exemplos encontrados no corpus com o verbo ter que com valor teleológico:

(38) a. É. Aqui é melhó que tem mais vizinho, tem mais folia... E lá... era parado, num tinha ninguém. Só a gente mesmo que morava. A num sê, pa vê alguma pessoa, a gente tinha que vim aqui em cima. (SP-inq01)

b. Tem que trabalhá também pra arranjá dinhero. (SP-inq02)

c. Mas quano a gente vai bebê, a gente tem que bota açúca que ele amarga a mesma coisa dos oto. (SP-inq03)

Em seguida será apresentado o resultado dos dados modais expressando modalidade bulética. 


\subsection{Modalidade bulética no corpus}

A modalidade bulética foi a que menos ocorreu. Foram apenas seis dados. Os únicos verbos que ocorreram nessa modalidade foram poder e ter que, cada um três vezes. Duas ocorrências de poder são no pretérito imperfeito podia e uma ocorrência é no presente do indicativo pode. Coincidentemente, todos os dados buléticos com poder foram da informante 05 (faixa etária 2, 57 anos).

Quanto a ter que, o inverso ocorreu: apenas um caso do pretérito imperfeito tinha que e dois casos do presente do indicativo, sendo um dado de tenho que e outro de tem que.

Abaixo, de (39) a (41), vemos exemplos de dados de modalidade bulética.

(39) DOC: Num pode, num vai ficá presa, né?

INF: É, num pode ficá não. Agora tô rezano pa entregá pa Deus que Deus vai resolvê isso tudo. (SP-inq05)

(40) a. Aqui teve segundo turno, podia ficá aquele... (SP-inq05)

b. Aí quando mesmo que Deus viu que eu num podia morrê daquela hora de parto. (SP-inq05)

(41) a. Eu penso, né, não sei se vai dá certo ô não a casa que primeiro eu tenho que fazê. (SP-inq02)

b. Aí tem vez que... tem gente aí que casa, né, mas... tem que dá certo casa ruim. (SP-inq04)

c. minha fia, tinha que passá ali, vinha de lá pra cá, aquele rojão brabo, daí a pouco ele desce. (SP-inq04)

\section{CONCLUSÕES}

O Quadro 1, abaixo, traz o resumo do sistema de verbos modais encontrado no corpus da comunidade de Sapé. 
Quadro 1: Sistema modal da comunidade de Sapé

\begin{tabular}{|l|c|c|c|c|c|}
\hline \multirow{2}{*}{ Força modal } & \multicolumn{5}{|c|}{ Tipo de modalidade } \\
\cline { 2 - 6 } & Epistêmica & Deôntica & Dinâmica & Teleológica & Bulética \\
\hline Possibilidade & Poder & Poder & $\begin{array}{c}\text { Poder } \\
\text { Dar para }\end{array}$ & - & Poder \\
\hline Necessidade & $\begin{array}{c}\text { Dever } \\
\text { (presente } \\
\text { indicativo) }\end{array}$ & $\begin{array}{c}\text { Dever } \\
\text { (pretérito) } \\
\text { Ter que }\end{array}$ & Ter que & Ter que & Ter que \\
\hline
\end{tabular}

Fonte: Elaborado pelos autores.

Com relação às perguntas levantadas na seção de Metodologia, os resultados da descrição do corpus trazem as seguintes respostas.

Quanto a ter que e dever, os dados confirmam a hipótese sobre a expansão de ter que, assumindo o lugar de dever em contextos não-epistêmicos, mas não em contextos epistêmicos. Os dados não-epistêmicos de dever se mostraram ainda mais raros do que o esperado inicialmente.

Quanto aos tipos de modalidade codificada por ter que, este modal ocorre em todos os tipos, com exceção da epistêmica (há um único dado, que consideramos ambíguo). No contexto epistêmico, dever pode ser considerado ainda o único modal que expressa o valor de necessidade.

Quanto à lexia dar para, todos os dados ocorreram na modalidade dinâmica, concorrendo com poder, mas ainda sem ameaçar a predominância desse verbo. Além disso, todos os dados de dar para ocorrem sem alçamento de algum sintagma para o sujeito, que permanece nulo.

Quanto às formas flexionais de dever, temos uma distribuição complementar no corpus, com as formas do presente aparecendo em contexto epistêmico. Os poucos dados deônticos trazem a flexão do pretérito imperfeito ou do futuro do pretérito. Isso favorece a hipótese levantada por Scarduelli (2011) quanto a deve e devia corresponderem a modais distintos no PB.

Quanto a poder, este se mostra o modal mais produtivo do corpus, ocorrendo com alta frequência e aparecendo em todos os tipos de modalidade, com exceção da teleológica, onde não houve nenhum dado com o valor de 
possibilidade. Também é o modal que apresenta a maior quantidade de flexões distintas. Entretanto, não houve dados da forma subjuntiva possa sendo usada em contexto matriz.

Uma vez que a pesquisa foi realizada com corpus de uma comunidade afrodescendente relativamente isolada, existe como pano de fundo a questão sobre qual papel desempenhou o contato linguístico na definição desse perfil dos modais e das mudanças linguísticas ocorridas no sistema modal desse dialeto e, de modo mais amplo, de todo o PB. Sendo este um trabalho inicial (e por questões de espaço), não trazemos respostas definitivas sobre essa questão, mas os resultados não refutam a hipótese de uma mudança induzida por contato (embora sejam não compatíveis apenas com essa causa). Esta pesquisa será complementada com dados (que já estão sendo analisados) de outras comunidades originadas a partir de forte contato linguístico, bem como comparar os resultados com o de outras pesquisas sincrônicas e diacrônicas sobre o fenômeno em dialetos não-marcados etnicamente, de modo a traçar um perfil mais abrangente da variação dialetal para a expressão do sistema modal no PB, bem como o perfil de sua evolução diacrônica.

\section{REFERÊNCIAS}

AUGUSTO, Evelin Azambuja. A expressão da modalidade em peças cariocas: uma análise diacrônica. Dissertação (Mestrado) - Universidade Federal do Rio de Janeiro, Rio de Janeiro, 2015.

COELHO, Sueli Maria; SILVA, Silmara Eliza de Paula. O continuum de gramaticalização do verbo DAR: de predicador a auxiliar. SCRIPTA, Belo Horizonte, v. 18, n. 34, p. 23-40, $2^{\mathrm{o}}$ sem. 2014.

DUARTE, Eugenia. A expressão da modalidade deôntica e epistêmica na fala e na escrita e o padrão SV. Revista do GELNE, n. especial, 77-94, 2012.

von FINTEL, Kai. Modality and language. In: BORCHERT, Donald M. (ed.), Encyclopedia of philosophy - 2 ed., v. 10. Detroit: MacMillan, 2006, p. 20-27.

LUCCHESI, Dante; BAXTER, Alan; RIBEIRO, Ilza (orgs.). O português afro-brasileiro. Salvador: EDUFBA, 2009. 
LUNGUINHO, Marcus Vinícius. Sobre a concordância modal em português. Cadernos de Sociedade e Linguagem, v. 11, n. 2, p. 117-140, 2010.

NEVES, Maria Helena de Moura. Imprimir marcas no enunciado. Ou: a modalização na linguagem. In: Texto e Gramática. Editora Contexto, 2006, p. 151-221.

PALMER, Robert F. Mood and Modality. 2. ed. Cambridge: Cambridge University Press, 2001.

PESSOTTO, Ana Lúcia. 'Pode' e 'podia': uma proposta semântico-pragmática. Revista da ABRALIN, v. 10, p. 11-41, 2011.

PESSOTTO, Ana Lucia. Epistemic and gradable modality in Brazilian Portuguese: a comparative analysis of 'poder', 'dever' and 'ter que'. ReVEL, special issue 8, 2014.

PIRES DE OLIVEIRA, Roberta. Apresentação: a modalidade na semântica formal das línguas naturais. ReVEL, edição especial n. 8, 2014.

SCARDUELLI, Jaqueline. 'Deve' e 'Devia': os limites da significação. Dissertação (Mestrado) - Universidade Federal de Santa Catarina, Centro de Comunicação e Expressão, Santa Catarina, 2011.

Nota do editor:

Artigo submetido para avaliação em: 30 de setembro de 2020 .

Aprovado em sistema duplo cego em: 01 de março de 2021. 